lived 15 hours. One was born by induotion of labour at eight months. 'The child was stillborn.

It will be noticed that in three cases labour was artificially induced, and of the children two out of the three were saved and are alive now, April, 1908, whereas in the three cases where labour came on prematurely of itself two out of the three children were lost.

As regards symphysiotomy and Cæsarean section in this case, both operations were performed only after failure to effect delivery of a living child by the forceps. It may be asked why symphysiotomy was not performed on the second occasion instead of Crasarean section. One reason was that there were grounds for believing that the pubic bones after the symphysiotomy were united partly by bony union. The other chief reason was that $I$ much prefer Cæesarean section to symphysiotomy. I believe the former to be little, if at all, more dangerous, while the convalescence after it is so much more rapid and satisfactory. From the point of view of the child it runs little or no risk in Casarean section but a very definite risk in symphysiotomy. The success of the latter as regards the child depends largely on a very accurate estimation of the pelvic measurements and also of the size of the child's head. While the pelvis may generally be measured with approximate accuracy the size of the child's head in relation to it must be more or less an uncertain factor. For my part, I agree with Whitridge Williams in feeling very little inclination to perform symphysiotomy rather than Cæsarean section in future.

Upper Brook-street, $W$.

\section{SOME POINTS ABOUT PUNCTURE OF THE BRAIN.}

BY Profegsor H. TILLMANNS, M.D.

PUNCTURE of the brain, like trephining, is a very old operation and was practised at the time of Hippocrates. In recent times particular attention has been paid to this operation by Middeldorpf, Souchon, Schmide, Kocher, Payr, and more especially by Neisser and Pollack. Neisser and Pollack have written a long treatise on the subject. They cite 36 cases in which puneture of the brain was performed 136 times. We certainly gatber from their observations that in suitable cases excellent results may be obtained from puncture of the brain both from the diagnostic and from the therapeutic point of view. It is remarkable that puncture of the brain has not been more universally stadied. We find little or no mention of the operation in the handbooks on internal medicine or on neuropathology. As in the case of lumbar puncture, puncture of the brain will certainly come to be more universally practised, both for the purpose of diagnosis and also for treatment of diseases of the brain.

A diagnostic, that is an exploratory, puncture is indicated in all cases where the diagnosis is uncertain. Where injury or disease of the cranial cavity or of the brain is evident, the typical trephining operation will of course be performed. A diagnostic puncture is indicated when there are signs of pressure on the brain or when an accumulation of blood, pus, or other fluid is suspected either in the cranial cavity, in the brain itself, or in the ventricles of the brain; also in the cases of cysts, tumours, foreign bodies, \&c. In certain cases the diagnostic puncture must be immediately followed by the definite operation-that is, trephining and removing the cause of the disease. Neisser and Pollack in particular have shown that even in advanced cases of pressure on the brainfor instance, in cases of intracranial hæmorrhage, extravasation, cysts, \&c.-puncture can give excellent results and bring about cures which could hardly be expected.

Therapeutical puncture has been principally practised in cases of hydrocephalus, dropsy of the ventricles (in some cases with subsequent drainage), and also for the purpose of making injections-for instance, of tetanus antitoxin in cases of tetanus-into the cranial cavity, into the brain itself, or into the lateral ventricles. This intracranial injection of tetanus antitoxin has rightly been abandoned in favour of subcutaneous injections, into the veins, or better into the spinal cord, and of endoneural injections, particularly into the larger nerves which must previously be laid

1 Neisser and Pollack: Mittheilungen aus dem Grenzgebeiten der Medizin und Chirurgie, Fand xiii., Hefte 4 and 5 . bare. For instance, in the case of wounds to the hand where tetanus is suspected, I recommend, as do Anschütz and others, an immediate prophylactic injection of tetanus antitoxin into the exposed brachial plexus, as tetanus poison, according to the experiments of Hans Meyer and Ransom, only reaches the central nervous organs through the axis cylinders of the motor nerves. This endoneural injection of tetanus antitoxin is particularly efficacious, when made prophylactically, before the appearance of the actual tetanus symptoms.

The technique of aseptic puncture of the brain is as follows. The preliminaries are the same as for trephining: shaving of the particular part of the scalp, in some cases of the whole head, and thorough cleansing of the same with soap, spirits of soap, ether, benzene, or alcohol. We generally employ local anæsthesia with cocaine-adrenalin or novocaine-adrenalin or, if necessary, general anæsthesia. The spot where the operation is to be performed can be fixed, if necessary, with a craniometer. The point is found partly by studying the existing symptoms-for example, of the probable seat of a tumour, of an accumulation of blood or matter, of a cyst, \&c. In other cases the spot is arbitrarily fixed when it is decided to puncture the ventricle. Occasion. ally general circumstances have to serve as a guide to the point where the puncture is to be made. A lesion of the larger blood-vessels and of the cerebral sinuses must, of course, always be avoided. When the spot has been selected either a small incision is made down to the bone and the peri. osteum is pushed aside, or else section of the pericranium is avoided altogether. In the latter case a hand or electric brace, fitted with a round-headed Doyen or Sudeck drill is pressed firmly on to the skin, which is pierced at the same time as the bone below. When drilling through the bone it is advisable to press more firmly at first than later in order to avoid injuring the dura mater after piercing the inner table. Injury of the dura mater is best avoided by first using a broad-pointed, oval-shaped Doyen drill to pierce the cranium, and then using a ball-pointed. Doyen drill to pierce the inner table. With this drill an injury to the dura mater is impossible. Payr recommends using a drill fitted with a guard against cutting too deep. Hæmorrhage of the bone can be stopped by spreading on aseptic wax. When the cranium has been pierced a fine hollow needle fitted to a Pravaz syringe that closes well is inserted and suction is produced. This suction must be performed as delicately as possible so as to avoid causing hremorrhage. The fluid matter which is abstracted should, if necessary, be examined at once microscopically and bacteriologically. Should the puncture produce no result, or should it be impossible to elucidate the case sufficiently through the small aperture in the bone, the opening can be enlarged as required either with a larger ball-pointed Doyen drill or with a Dahlgren forceps in order, for instance, to judge the pulsation of the brain, intracranial pressure, \&c When a larger opening has been made the dura mater should be taken hold of with a small-pointed hook and cut crosswise with a very sharp thin knife. The suspected hæmorrhage, abscess, or cyst is then pierced with a fine hollow needle or a thicker one; grooved needles or a very fine sharp knife can also be used. In cases of tumour this simple aseptic piercing of the cranium with the ball-pointed Doyen drill is also devoid of danger, and Neisser and Pollack have shown that with the abovementioned simple puncture the presence of a tumour can be discovered-for instance, in the frontal lobe of the brainwhere it had not been expected and where it would have been impossible to ascertain its existence in any other way. If necessary the puncture can be repeated, as the operation is relatively simple. Neisser once punctured nine times in succession and finally succeeded in locating the suspected tumour. In the cases of newly born children and of hydrocephalus it is usually not necessary to pierce the bone. The cranium is opened at a suitable membranous spot where there is neither a large blood-vessel nor a cerebral centrefor instance, next to the sinus longitudinalis.

Various points of the cranium have been recommended for the puncture of the lateral ventricle. This operation is especially indicated when there is an accumulation of liquid in the same, particularly in cases of hydrocephalus internus. In certain cases the puncture is combined with a subsequent drainage of the ventricle. The motor arca, the neighbourhood of the fissure of Sylvius, and the known centres of 
special sense are to be avoided. Von Bergmann entered the cranium from in front, close over and to the inner side of the frontal eminence, and inserted the hollow needle through the frontal lobe of the brain backwards and keeping to the inner side. Keen punctured the lateral ventricle from the side in the following manner. The cranium was opened 3 centimetres behind and 3 centimetres above the external auditnry meatus - that is, 3 centimetres above Reid's base line, which is drawn from the lower border of the orbit through the middle of the meatus. The needle is inserted in the direction of an imaginary point 6 centimetres vertically above the external auditory meatus of the other side and through the second temporal convolution. From $4 \frac{1}{2}$ to 5 centimetres deep lies the lateral ventricle of the brain in the course or at the beginning of the descending cornu. Keen performed the operation of puncturing, draining, and irrigating the lateral ventricles with satisfactory results. Mayo Robson aiso recommends puncturing the ventricles from the side, but through the first temporal convolution.

As do Kocher, Neisser, and Pollack, I recommend puncturing the ventricle from above, through the frontal bone about 2 centimetres from the central line and 3 centimetres from the precentral fissure. The hollow needle must be pushed downwards and backwards. You strike the ventricle at a depth of from 5 to 6 centimetres. The ventricles can also be drained very well from above. Care must be taken not to insert the drainage-tube too deeply into the ventricle, so as to avoid injuring the opposite wall. This can easily be avoided by fitting a ring or shield to the tube.

As it offers so little danger of infection, subcutaneous drainage is most advantageous. For a really efficacious draining of the ventricle Payr recommends transplanting living pieces of human arteries, taken, for instance, from the arteria radialis or brachialis, into the lateral ventricle in such a way that the other end becomes grafted in the sinus longitudinalis. In this way the serous fluid from the ventricle is carried away by the blood. This operation can naturally only be successful when performed in the best way in every respect. From what we know to-day of transplantation it may reasonably be expected that living pieces of artery can be thus grafted into the ventricle and sinus longitudinalis.

Finally, the ventricle may also be punctured from behind, from the occipital lobe. According to von Beck the tip of she posterior cornu is met with at a depth of about 3 centimetres, if the cranium is opened 4 centimetres over the protuberantia externa and 3 centimetres to the side of the central line of the skull, in which case the needle is inserted in a forward and slightly upward direction.

Leipsic.

NOTES ON

\section{OPERATIONS PERFORMED UNDER SPINAL AN ÆESTHESIA (COCAINE OR STOVAINE) BY TUFFIER'S METHOD.}

BY Dr. SABADINI,

SURGEON TO THE CIVIL HOSPITAL, ALGIERS.

(Translated for the Author by ALFRED S. GUBB, M.D. PARIS.)

IN August and September, 1903, even before Dr. Fourneau read his paper on stovaine at the Académie des Sciences (February, 1904) and Chaput his communication to the Société de Biologie (May 2nd, 1904) I found, in the course of a visit to various hospitals of Paris, the provinces, and abroad, that the majority of surgeons were ignorant of this method of inducing surgical anæsthesia, while some indeed frankly stated their view that the method was absolutely unphysiological and dangerous. Of the latter it was evident that none of them had ever tried it and their statements were obviously based merely on impressions derived from the medical journals. Yet the remarkable publications of Leonard Corning and of Tuffier (1889), the inventor of the method, and of his pupils, Cadol and Nicolendorff, the contributions by Nicoletti of Naples, Professor Bier of Kiel, and his assistant Eden, and those of Schiani and Durante of Italy, had peremptorily established the fact that the introduction of cocaine into the spinal column produced widespread anæsthesia without circuiatory or respiratory disturbance and that cocarne determinod no grave ehanges in contact with the nerve elements. Since that time numerous articles have appeared in the various medical journals in France and elsewhere by surgeons who have practised this method of anæsthetisation with satisfaction to themselves and benefit to their patients.

Why, then, this ostracism or this indifference in regard to a method which had been fully tried? In part no doubt to the attacks of Réclus and Laborde, the latter, by the way, being a physiologist and not a clinician, but neither attack was supported by any weighty reasons. Legueu's two mishaps and Broca's fatality, neither of which could fairly be attributed to the cocaine, seem to have made surgeons hesitate. My object in publishing my statistics of spinal cocainisation is to show that lumbar anæsthesia is in no wise dangerous and that the accusations which have been levelled at the method by its detractors are without foundation.

\section{Spinal Cocainisation.}

It was in July, 1900, that I for the first time saw Tuffier practise spinal anæsthetisation at the Lariboisière Hospital for the removal of a uterine fibroid. The anæsthesia was complete and was not attended by any untoward incident. On my return to Algiers I at once put the method into practice, so that my experience dates from August, 1900.

I may state at once that I have never imposed spinal cocainisation on my patients. Having proposed it, in the event of refusal I gave chloroform or other general anæsthetic according to circumstances. The cases comprise operations of every degree of severity: resection of ribs, hydatid cysts of the liver and peritoneum, strangulated hernia, abscess of the liver, eventration, incised wounds of the abdomen and contained viscera, on the anus and rectum, with a very large proportion of operations on the genital organs of both male and female, and on the limbs.

Age.-The patients' ages varied from 15 to 93 years and age per se is not regarded as a contra-indication.

Nature of the operation. - -The operations performed under spinal anæsthesia were always low down-i.e., below the level of the umbilicus, anæsthesia extending upwards as a general rule to within two fingers' breadth below the mammæ. ${ }^{1}$ Yet I have removed three mammary cancers by this method and done one resection of the elbow for tuberculosis in a girl, aged 18 years. The dose in these four cases was 3 centigrammes for the first three and 4 centigrammes for the fourth. In order to insure diffusion of the cocaine I was careful to keep the patient in Trendelenburg's position for ten minutes after the injection but anæsthesia was not complete, and I was fain to have recourse to chloroform, so that I have not repeated the experiment. In empyema I usually resect the tenth $\mathrm{rib}$ and in these instances the anæsthesia was sufficient.

By employing spinal anæesthesia only in persons who willingly submit thereto one reduces the number of failures these in my experience amounted to about 11 per cent It is with cocaine as it is with ether and chloroform, by which I mean that there is such a thing as idiosyncrasy or rather that the anæsthetic dose varies according to the individual. I am inclined to think that if we adopted in respect of cocaine the procedure which Chaput has adopted for stovaine-that is to say, if a further injection of 1 or 2 centigrammes were made-complete anæsthesia might be obtained in every instance. It was noted that most resistance was shown by alcoholic and nervous subjects. I recall the case of a nervous woman with a double pyosalpinx who only reluctantly agreed to the injection and obliged me in the middle of the operation to call chloroform to my aid. Yet this very patient confided to her neighbour that as a matter of fact she did not feel anything but that the bandage having fallen from her eyes she saw her belly open and began to scream. This is not infrequently the case; the patient feels no pain but owing to a lack of surveillance they see what is going on and get alarmed, or it may be they feel when tissues are being dragged upon as during the removal of large nterine fibroids.

Immediate effects. - By this I mean the subjective phenomena between the fifth and the fifteenth minute after injection such as pallor, sweating, nausea, vomiting, and occasionally but rarely marked apprehension; and, secondly, epileptoid tremor of the lower limbs and fatal syncope.

I I have invariably employed Poullenc's solution 2 centigrammes ner bulb. 